\title{
PERANCANGAN SISTEM INFORMASI PENYEDIA JASA BINATU PADA CV SAFARI LAUNDRY
}

\author{
Ravi Zarazka Putra ${ }^{1}$, Rini Amalia ${ }^{2}$, Fitriyah Puspita ${ }^{3}$ \\ Program Studi Teknik Informatika, Fakultas Teknik dan Ilmu Komputer, \\ Universitas Indraprasta PGRI \\ Jalan Raya Tengah No 80, Kelurahan Gedong, Pasar Rebo, Jakarta Timur \\ ravi.zaraska@gmail.com ${ }^{1}$, reen.amaleea@gmail.com ${ }^{2}$, fitriyahpuspita23@gmail.com ${ }^{3}$
}

\begin{abstract}
Abstrak
CV Safari Laundry adalah perusahaan penyedia jasa yang bergerak dibidang bisnis binatu kiloan dengan konsep cuci dan setrika. Dalam Proses transaksi, penerimaan binatu masih dicatat dalam nota, tanda bukti atau faktur antara penjual dan pelanggan tidak ada backup data dan laporan transaksi masih dilakukan secara manual. Oleh karena itu tujuan dari penelitian ini adalah merancang sistem informasi penyedia jasa binatu berbasis desktop pada CV Safari Laundry, sehingga sistem informasi binatu akan lebih efisen dan efektif. Metode Penelitian yang digunakan adalah metode waterfall, dimana perancangan sistem yang baru untuk menggantikan sistem yang lama secara keseluruhan atau memperbaiki sistem yang telah ada. Pada penelitian ini telah dirancang sebuah sistem informasi penyedia jasa binatu bebasis desktop pada CV Safari Laundry dengan alat bantu perancangan sistem Diagram Aliran Data (DAD), Entity Relationship Diagram (ERD), dengan bahasa pemrograman Java dengan Netbeans IDE, dan database MySQL menggunakan Xampp. Perancangan sistem informasi penyedia jasa binatu memiliki beberapa hasil keluaran yaitu tentang laporan daftar pelanggan, laporan status pencucian, laporan pembayaran, laporan rinci laundry.
\end{abstract}

Kata Kunci: perancangan, sistem informasi, penyedia jasa binatu.

\begin{abstract}
CV Safari Laundry is a service provider company engaged in the kilogram laundry business with the concept of washing and ironing. In the transaction process, laundry receipts are still recorded in notes, proofs or invoices between sellers and customers, there is no data backup and transaction reports are still done manually. Therefore the aim of this study is to design a desktop-based laundry service provider information system on CV Safari Laundry, so that the laundry information system will be more efficient and effective. The research method used is the waterfall method, where the design of a new system is to replace the old system as a whole or to improve existing systems. In this study, a desktop-based laundry service provider information system on CV Safari Laundry has been designed with a Data Flow Diagram (DAD) system design tool, Entity Relationship Diagram (ERD), with the Java programming language with Netbeans IDE, and MySQL database using Xampp. The design of a laundry service provider information system has several outputs, namely customer list reports, laundry status reports, payment reports, and detailed laundry reports.
\end{abstract}

Keywords: design, information systems, laundry service provider.

\section{PENDAHULUAN}

CV Safari Laundry yang terletak di kota Tanggerang adalah perusahaan penyedia jasa yang bergerak dibidang bisnis binatu kiloan dengan konsep cuci dan setrika. Proses administrasi pada CV Safary Laundry masih dilakukan secara manual seperti kegiatan pendaftaran pelanggan, transaksi dan pembuatan laporan. Kegiatan yang masih dilakukan secara manual mengakibatkan antrian pelanggan, keluhan dari pelanggan, dan ketidakakuratan data dalam penyusunan laporan. Berdasarkan latar belakang masalah yang telah diuraikan, maka penulis merumuskan beberapa masalah yaitu Bagaimana sistem jasa binatu pada CV Safari Laundry yang sedang berjalan, bagaimana mengumpulkan data-data pengolahan jasa binatu pada CV Safari Laundry yang dibutuhkan sesuai dengan perancangan sistem informasi yang akan di buat, bagaimana merancang sistem informasi penyedia jasa binatu pada CV Safari Laundry. Dengan mengidentifikasi sistem jasa laundry yang sedang berjalan pada CV Safari Laundry dan mengumpulkan data-data pengolahan jasa laundry yang dibutuhkan sesuai dengan perancangan sistem informasi yang akan di bangun, maka akan dirancang sistem informasi penyedia jasa binatu pada CV Safari Laundry 
secara sistemastis, terstruktur, dan terarah sehingga dapat digunakan oleh CV Safari Laundry untuk mengatasi ketidakefektifan dan ketidakefisien sistem manual yang digunakan saat ini.

\section{PENELITIAN YANG RELAVAN}

Dalam penelitian yang berjudul Perancangan Sistem Aplikasi Laundry Di PT Anugrah Kurnia Primatama dengan peneliti yang bernama Nugiat Okkatis memiliki hasil penelitian adanya Perancangan Sistem Aplikasi Laundry Di PT Anugrah Kurnia Primatama maka pekerjaan dapat dilakukan dengan efektif dan efisian. Tujuan dari penelitian ini merupakan upaya untuk membuat sistem aplikasi di PT Anugrah Kurnia Primatama yang belum terkomputerisasi dan masih menggunakan cara yang manual. Dari penelitian ini diharapkan pembuatan sistem informasi yang dihasilkan nantinya akan mampu mengatasi dari sistem yang belum terkomputerisasi (Okkatis, 2016).

Dalam penelitian yang berjudul Perancangan Sistem Informasi Jasa Laundry Pada Resik Laundry Berbasis Java dengan peneliti yang bernama Dwi Kurniawan Sutanto memiliki hasil penelitian adanya Perancangan Sistem Informasi Jasa Laundry Pada Resik Laundry Berbasis Java.Tujuan dari penelitian adalah merancang sebuah sistem informasi laundry untuk mempermudah pengelolahan pada Resik Laundry secara terperinci dengan menggunakan aplikasi Java dan MySQL, sehingga dapat meminimalkan kehilangan data pelanggan pada Resik Laundry. Dari penelitian ini Maka pekerjaan dapat dilakukan dengan efektif dan efisien (Sutanto, 2017).

Dalam penelitian yang berjudul Perancangan Sistem Informasi Laundry Berbasi Desktop Pada Toko Amanah Laudnry dengan peneliti yang bernama Asih Fajarwati memiliki hasil penelitian adanya Perancangan Sistem Informasi Laundry Berbasis Desktop Pada Toko Amanah Laundry. Tujuan dari penelitian adalah mengidentifikasi hambatan dan masalah dalam pengolahan data pada Toko Amanah Laundry. Untuk membantu kebutuhan pelayanan Toko Amanah Laundry dalam pengolahan data agar lebih terorganisir dan lebih efektif, sehingga meningkatkan kualitas pelayanan Toko Amanah Laundry. Dari penelitian ini diharapkan dapat mempermudah kinerja anggota dan pengelolahan pada Amanah Laundry dari kegiatan pengiputan, proses, dan output (Fajarwati, 2018).

Dalam penelitian yang berjudul Sistem Informasi Pengelolaan Data Laundry Pada Rumah Laundry Bekasi dengan peneliti yang bernama Susy Rosyida dan Very Riyanto memiliki hasil penelitian adanya pembuatan sistem pengelolaan data laundry untuk memudahkan pengguna dalam proses transaksi pengolahan data khususnya proses penyimpanan data pengguna, penyimpanan data pelayanan jasa laundry, penyimpanan data transaksi penerimaan jasa laundry, sampai dengan pembuatan laporan. Tujuan dari penelitian adalah untuk membantu rumah laundry Bekasi dalam pengelolaan data agar lebih rinci dan efektif. Dari Penelitian ini diharapkan dapat mempermudah operasional pada rumah laundry Bekasi (Rosyida \& Riyanto, 2019).

\section{METODE PENELITIAN}

Metode penelitian yang digunakan adalah model waterfall. Model waterfall adalah model klasik yang bersifat sistematis, berurutan dalam membangun software. Nama model ini sebenarnya adalah "Linear Sequential Model". Model ini sering disebut juga dengan "classic life cycle" atau metode waterfall (Pressman, 2015). Tahapan seperti gambar sebagai berikut:

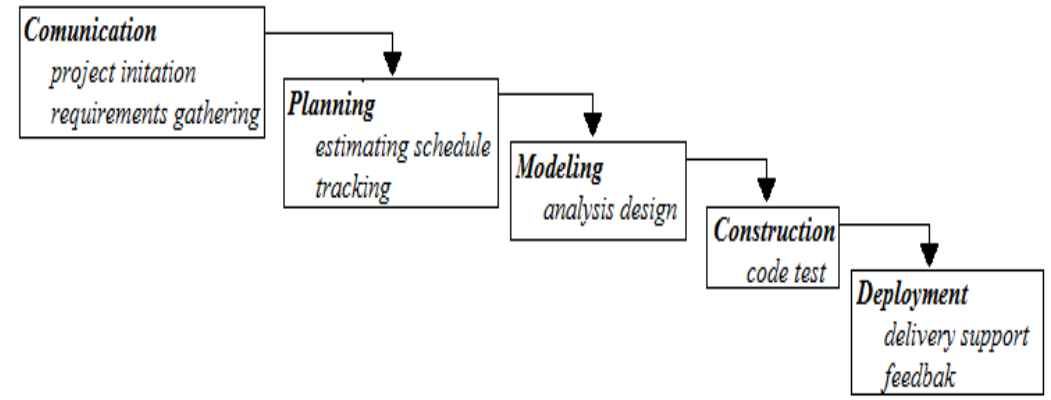

Gambar 1. Waterfall

(Sumber: Pressman, 2015) 
1. Communication (Project Initiation \& Requirements Gathering)

Sebelum memulai pekerjaan yang bersifat teknis, sangat diperlukan adanya komunikasi dengan customer demi memahami dan mencapai tujuan yang ingin dicapai. Hasil dari komunikasi tersebut adalah inisialisasi proyek, seperti menganalisis permasalahan yang dihadapi dan mengumpulkan data-data yang diperlukan serta membantu mendefinisikan fitur dan fungsi software.

2. Planning (Estimating, Scheduling, Tracking)

Tahap berikutnya adalah tahapan perencanaan yang menjelaskan tentang estimasi tugas-tugas teknis yang akan dilakukan, resiko apa yang dapat terjadi, sumber daya yang diperlukan dalam membuat sistem, produk kerja yang ingin dihasilkan, penjadwalan kerja yang akan dilaksanakan dan tracking proses pengerjaan sistem.

3. Modeling (Analysis \& Design)

Tahapan ini adalah tahap perancangan dan permodelan arsitektur yang berfokus pada perancangan struktur data, arsitektur software, tampilan interface dan algoritma program. Tujuannya untuk lebih memahami gambaran besar dari apa yang akan dikerjakan.

4. Contruction (Code \& Test)

Tahapan construction ini merupakan proses penerjemahan bentuk desain menjadi kode atau bentuk bahasa yang dapat dibaca oleh mesin. Setelah pengkodean selesai, dilakukan pengujian terhadap sistem dan juga kode yang sudah dibuat. Tujuannya untuk menemukan kesalahan yang mungkin terjadi untuk nantinya diperbaiki.

5. Deployment (Delivery, Support, Feedback)

Tahapan deployment merupakan tahapan implementasi software ke customer, pemeliharaan software secara berkala dan pengembangan software berdasarkan umpan balik yang diberikan agar sistem dapat berjalan dan berkembang sesuai fungsinya.

\section{HASIL DAN PEMBAHASAN}

Penelitian ini telah berhasil membuat aplikasi sistem Informasi Penyedia Jasa binatu, sehingga pencatatan data pelanggan, data layanan, data transaksi lebih rapi dan terjaga dengan baik. Pembuatan laporan, baik laporan daftar pelanggan, laporan status pencucian, laporan daftar pembayaran dan laporan rinci laundry dapat diakses dengan cepat.

\section{Diagram Alir Data (DAD)}

Data Flow Diagram (DFD) atau dalam bahasa Indonesia menjadi Diagram Alir Data (DAD) adalah representasi grafik yang menggambarkan aliran informasi dan transformasi informasi yang diaplikasikan sebagai data yang mengalir dari masukan (input) dan keluaran (output) (Shalahuddin, 2013). Pendapat ini juga didukung oleh (Muslihudin \& Oktafianto, 2016). 


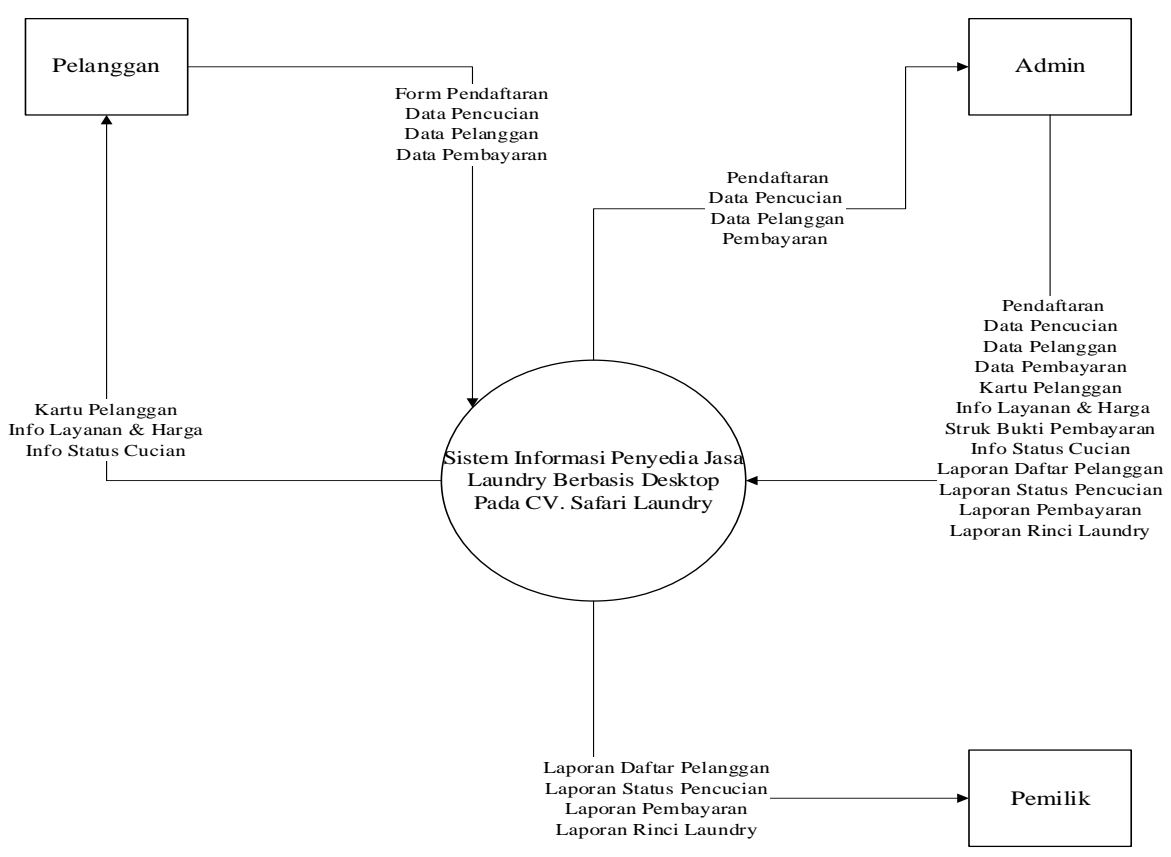

\section{Normalisasi}

Gambar 2. Diagram Konteks

Normalisasi adalah teknik dengan melakukan sebuah pendekatan bottom-up yang digunakan dalam membantu mengidentifikasikan hubungan (Indrajani, 2015). Dalam normalisasi terdapat penjabaran data yang saling berkaitan (Kusrini, 2007). Berikut bentuk normalisasi dari sistem informasi penyedia jasa binatu pada CV Safari Laundry:

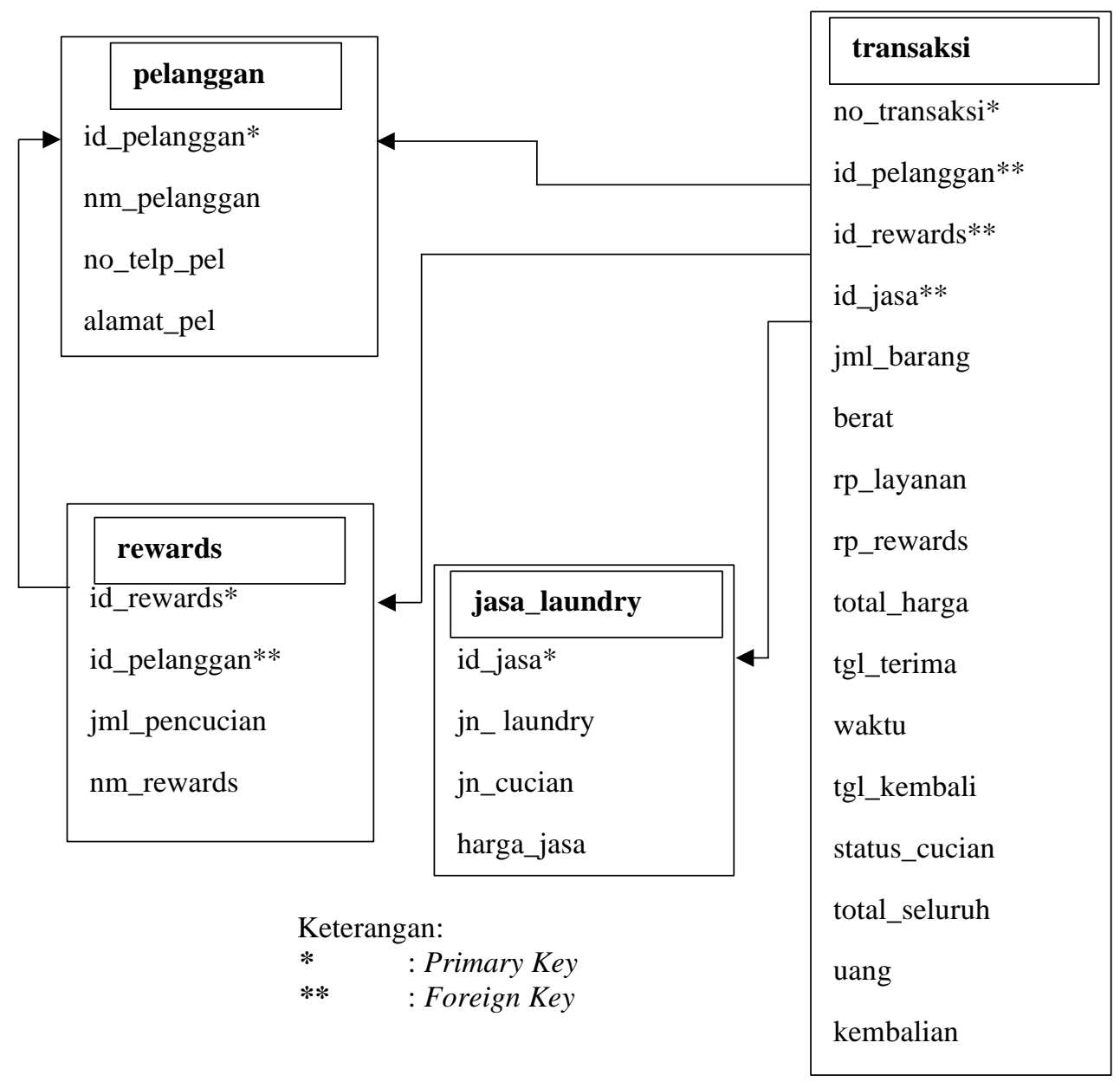

Gambar 3. Normalisasi 


\section{Entity Relationship Diagram (ERD)}

Entity Relationship modeling adalah sebuah pendekatan top-bottom dalam merancang sebuah basis data, dimulai dengan mengidentifikasikan data yang penting dan digambarkan dalam suatu model (Indrajani, 2015). Pendapat ini juga didukung oleh (Priyadi, 2014).

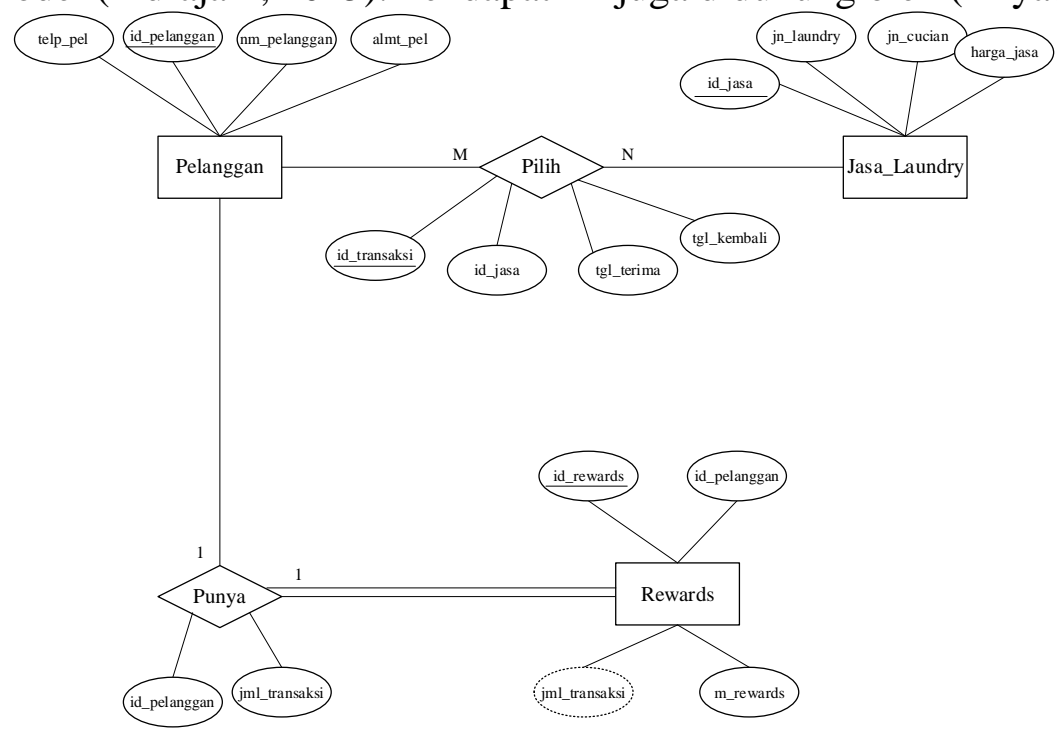

Gambar 4. Entity Relationship Diagram (ERD)

\section{Tampilan Layar}

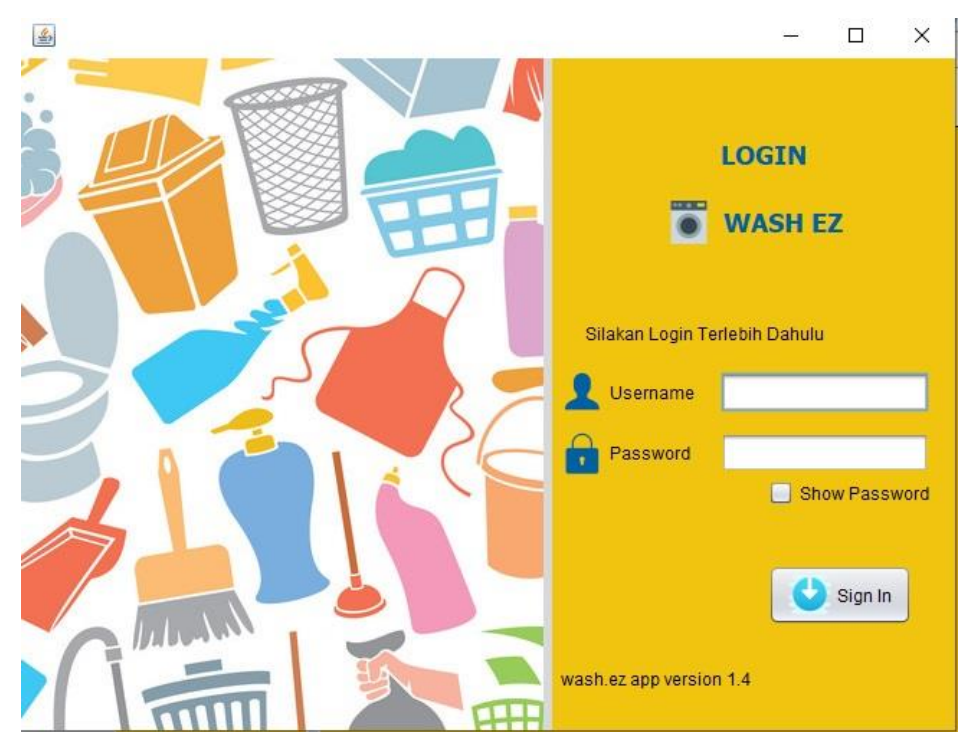

Gambar 5. Tampilan Layar Login

Tampilan ini terdapat pada awal program. Menu Login merupakan gerbang utama untuk dapat masuk ke dalam aplikasi. Pengguna memasukkan username dan password. Username dan password tersebut telah tersimpan dalam database. Apabila username dan password yang tidak sesuai dengan yang ada dalam database, maka pengguna tidak dapat masuk ke dalam aplikasi. Tombol Signin untuk menyimpan data yang telah dimasukkan kemudian dicocokkan dengan database. Untuk melihat atau mengkoreksi password bisa menekan kotak cek show password. 


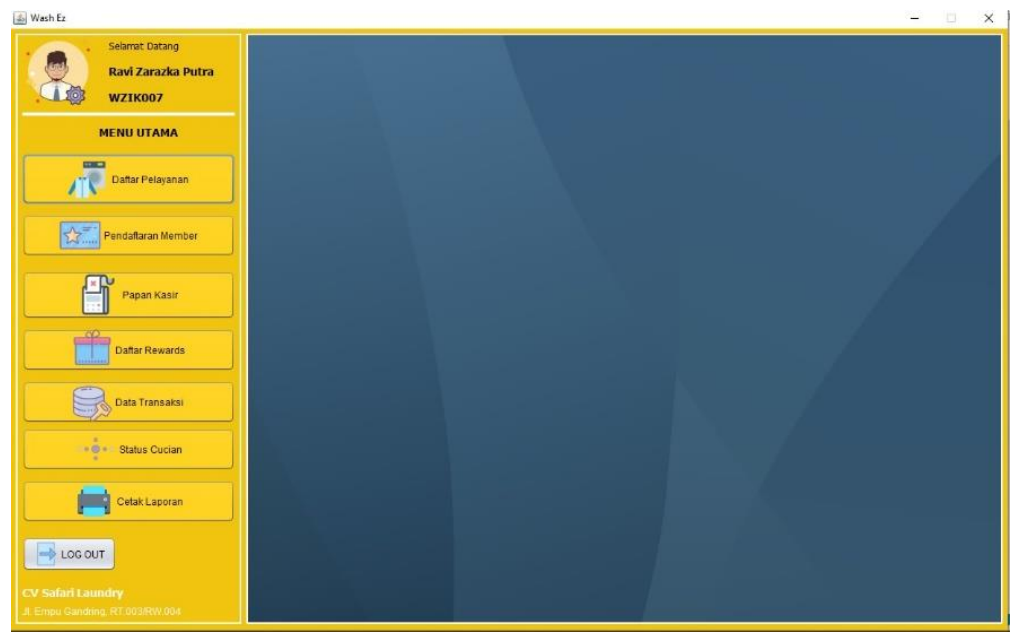

Gambar 6. Tampilan layar Menu Utama

Form menu utama ini merupakan form utama untuk memanggilseluruhform lainnya. Melalui form ini, aplikasi penyedia jasa laundry inidijalankan. Pertama masuk akan disuguhkan ucapan selamat datang dan tertera nama dan id yang melakukan login. Terdapat dua panel yang memiliki fungsi berbeda; panel pertama untuk menaruh button yang ada pada menu utama, panel kedua berupa desktop pane berfungsi untuk menampilkan layer sesuai dengan perintah memunculkan layer pada panel menu utama.

Pada menu utama terdapat tujuh button untuk menampilkan layer lainnya, tampilan layer akan muncul pada panel kedua yaitu panel desktop pane.

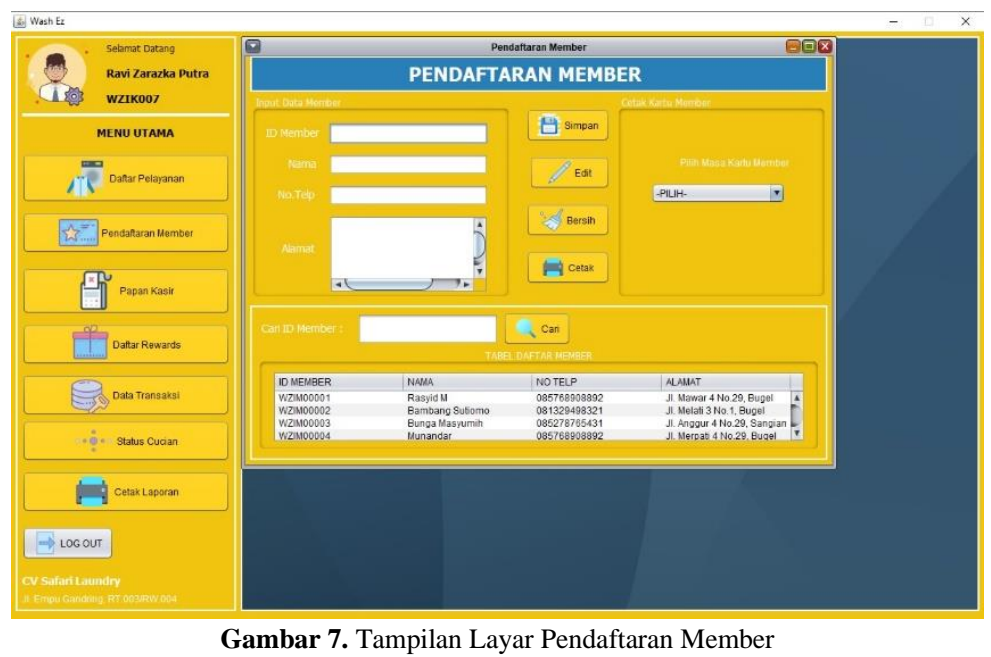

Format masukan data pelanggan; kode jasa berupa variabel char berisi 9 karakter yang terotomatis ter-input, pilih jenis laundry dengan pilihan dalam combo box, pilih jenis cucian dengan pilihan dalam combo box, masukan harga jasa dengan angka maksimal 25 angka. Setelah semua diterinput maka tekan tombol simpan. Kolom pencarian data layanan dengan ketikan jenis laundry maksimal100 karakter lalu tekan tombol cari. Untuk mengubah data dengan klik pada tabel dan ubah data yang berada pada panel input data lalu tekan tombol ubah. Untuk mencetak kartu member pilih jenis kartu lalu tekan tombol cetak. 


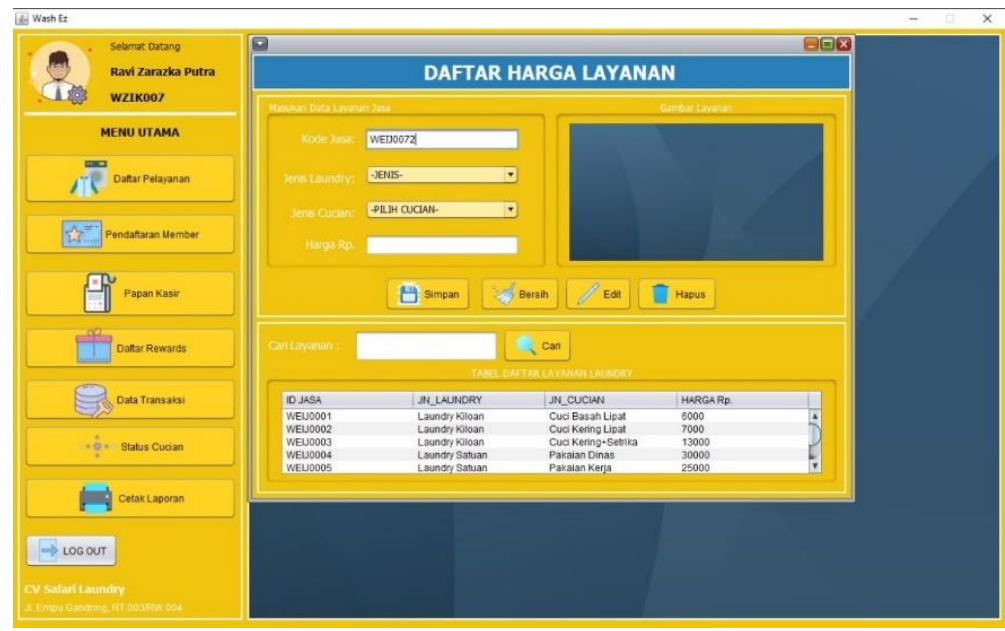

Gambar 8. Tampilan Layar Daftar Pelayanan

Format masukan data pelayanan; kode jasa berupa variabel char berisi 9 karakter yang terotomatis ter-input, pilih jenis laundry dengan pilihan dalam combo box. Pilih jenis cucian dengan pilihan dalam combo box. Masukan harga jasa dengan angka max 25 angka. Kolom pencarian data layanan dengan ketikan jenis laundrymax 100 karakter.

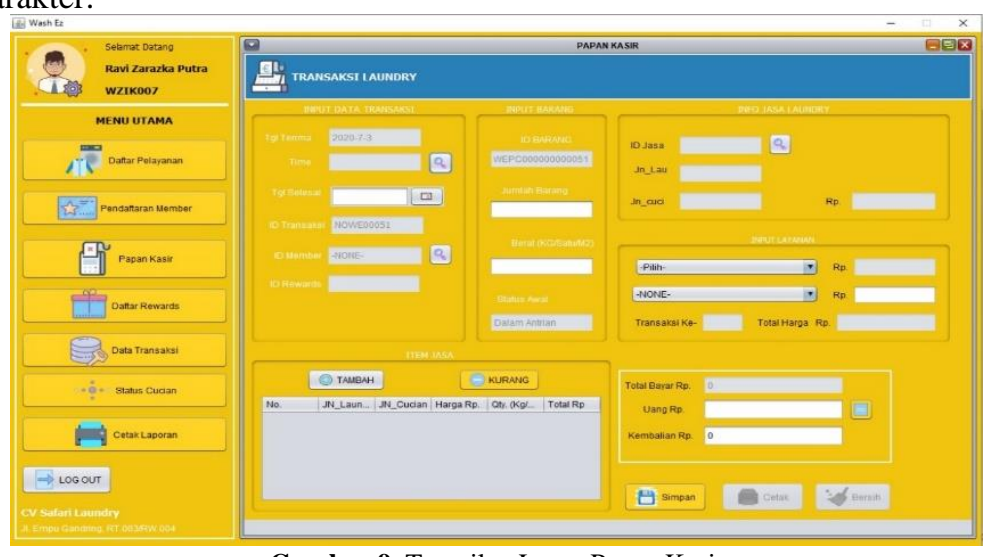

Gambar 9. Tampilan Layar Papan Kasir

Format masukan form papan kasir untuk data transaksi; terdapat 5 panel, panel pertama input data transaksi ter-input otomatis jika menekan tombol cari dan pilih tanggal di calender. Panel input barang terdapat id barang dengan karakter terinput otomatis, masukan jumlah barang dengan angka maksimal 25 angka, dan masukan berat dengan angka. Panel info jasa laundry input otomatis jika meneka tombol cari. Panel input layanan dengan pilih pada combo box dan input akan terotomatis.

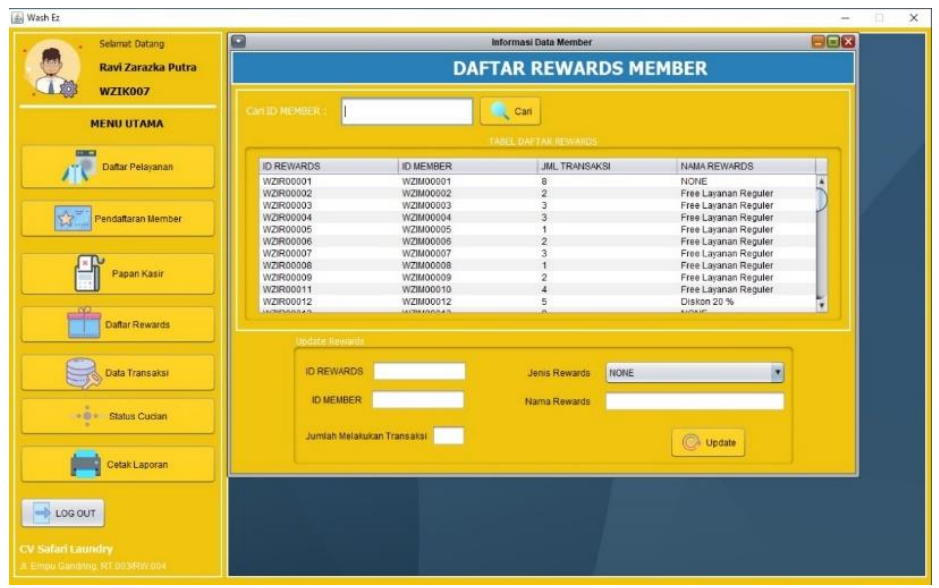

Gambar 10. Tampilan Layar Daftar Rewards 
Format daftar rewards; kolom cari ketikan id member dan data akan muncul ditabel daftar rewards. Untuk update data dengan menekan data pada tabel maka akn muncul pada kolom dan pilihan combo box dan tekan tombol update.

\section{SIMPULAN}

Dengan adanya sistem informasi penyedia jasa laundry ini, mempermudah bagian admin dalam mengelola proses pengelolaan dan pencatatan data pelanggan, data layanan dan data transaksi serta pembuatan laporan, baik laporan daftar pelanggan, laporan status pencucian, laporan daftar pembayaran dan laporan rinci laundry dapat diakses dengan cepat.

\section{DAFTAR PUSTAKA}

Fajarwati, A. (2018). Perancangan Sistem Informasi Laundry Berbasis Desktop Pada Toko Amanah Laundry. Universitas Indraprasta PGRI Jurusan Teknik Informatika.

Indrajani. (2015). Database Design (Case Study All In One). PT Elex Media Komputindo.

Kusrini. (2007). Strategi Perancangan dan Pengelolaan Basis Data (A. Triyuliana (ed.); Edisi I). CV Andi Offset.

Muslihudin, M., \& Oktafianto. (2016). Analisis dan Perancangan Sistem Informasi Menggunakan Model Terstruktur dan $U M L$ (A. Pramesta (ed.); Edisi I). CV Andi Offset.

Okkatis, N. (2016). Sistem Aplikasi Laundry di PT Anugrah Kurnia Primatamaitle. Universitas Indraprasta PGRI Jurusan Teknik Informatika.

Pressman, R. S. (2015). Rekayasa Perangkat Lunak (Pendekatan Praktisi) Buku 1. Andi.

Priyadi, Y. (2014). Kolaborasi SQL Dan ERD Dalam Implementasi Database (I). Andi Publisher.

Rosyida, S., \& Riyanto, V. (2019). Sistem Informasi Pengelolaan Data Laundry Pada Rumah Laundry Bekasi. JITK (Jurnal Ilmu Pengetahuan Dan Teknologi Komputer), 5(1), 29-36. https://doi.org/10.33480/jitk.v5i1.611

Shalahuddin, M. dan R. A. S. (2013). Rekayasa Perangkat Lunak Terstruktur dan Berorientasi Objek. Informatika.

Sutanto, D. K. (2017). Perancangan Sistem Informasi Jasa Laundry Pada Resik Laundry Berbasis Java. Universitas Indraprasta PGRI Jurusan Teknik Informatika. 